\title{
Assessment of Agri-Resource Potential of West Georgia and Landscape Zoning for Dissemination Actinidia
}

\author{
Seperteladze Zurab ${ }^{1}$, Davitaia Eter ${ }^{1}$, Memarne Guram ${ }^{2}$, Khalvashi Neli ${ }^{3}$, Gaprindashvili George ${ }^{4}$ \\ ${ }^{1}$ Faculty of Exact and Natural Sciences, Tbilisi State University, Tbilisi, Georgia \\ ${ }^{2}$ Batumi Shota Rustaveli State University, Institute of Phytopathology and Biodiversity, Batumi, Georgia \\ ${ }^{3}$ Batumi Shota Rustaveli State University, Institute of Phytopathology and Biodiversity, Division of Biodiversity Monitoring and Conservation, \\ Batumi, Georgia \\ ${ }^{4}$ Faculty of Exact and Natural Sciences, Tbilisi State University, Institute of Geography, Tbilisi, Georgia
}

\section{Email address:}

zura_sep@mail.ru (S. Zurab), eteri.davitaia@yandex.ru (D. Eter), plantimmunity@yahoo.com (M. Guram), nelikoo@mail.ru (K. Neli), gaprindashvili.george@gmail.com (G. George)

\section{To cite this article:}

Seperteladze Zurab, Davitaia Eter, Memarne Guram, Khalvashi Neli, Gaprindashvili George. Assessment of Agri-Resource Potential of West Georgia and Landscape Zoning for Dissemination Actinidia. Earth Sciences. Special Issue: Modern Problems of Geography and Anthropology. Vol. 4, No. 5-1, 2015, pp. 104-107. doi: 10.11648/j.earth.s.2015040501.29

\begin{abstract}
The methodology has been developed and established in West Georgia for agro-resource potential spatial distribution regularities for ACTINIDIA (according to hypsometric levels and types of landscapes of Georgia). On the basis of a large amount of data processing and systematization, also different data scattered in various scientific-research organizations agri-resource potential of West Georgia were determined. For Multiple database creation and processing, based on GIS technology. Conducted large-scale landscape zoning.
\end{abstract}

Keywords: Agro-climatic Zones, Standard-model, Landscape, Multifactor Analysis, Vegetation Period

\section{Introduction}

Estimation of the agro-resource potential of an area is much important to rationally grow some or other culture and identify the potential prospects to improve its productivity (harvest). The latter depends on many factors, with natural physical-geographical factor as one of the most important of them. This factor is multi-factorial and multi-dimensional. Application of a mathematical method allowing improving the geographical approach and providing a more objective and complex estimation of the area in this respect was considered by us as the most optimal way to solve this complex problem. This method also facilitates selecting and estimating the areas with their numerical values varying within a great range and with different dimensions.

By using the above-mentioned method by the authors $[4,5]$, the present work accents the kiwi culture commonly spread in west Georgia in recent period. The experimental plantations of kiwi (Actinidia chinensis) are grown only in the low- and middle-mountainous landscape zones of Adjara-Guria segment, in west Georgia (even at $1200 \mathrm{~m}$ asl); however, the questions of optimal landscapes and zoning of the habitats of the given culture are not developed yet. With this thought in mind, we, a group of authors, in cooperation with agricultural technicians, who are practitioners [2], have developed and estimated the agro-climatic properties of kiwi culture, selected and identified the optimal natural conditions (without agricultural measures) (by designing a virtual standard model) and provided the landscape zoning of West Georgia by using GIS-analysis.

The major scientific novelty of the project is selecting and ranging the areas with the conditions optimal to grow kiwi by using a mathematical method, in particular, estimating (selecting and processing) the agro-climatic properties, designing a virtual standard model and providing the landscape zoning of the territory based on the proximity to the virtual standard model what will allow differentiating the territory for the given culture by considering its potential validity.

\section{Object of Research}

West Georgia, with its major part occupied by the landscapes of humid subtropical Kolkheti lowland has been 
known as a fertile and rich region since the ancient times. In addition to Kolkheti plain valley, it incorporates the landscapes of the Kavkasioni in the north, Meskheti ridge in the south and piedmonts of Imereti plateau and adjacent lowand average-mountain landscapes in the east. With its peculiar geographical location and owing to the Great Caucasus ("Kavkasioni") acting as a barrier, diversified relief forms, hypsometric extension, influence of the Black Sea and, most importantly, the resultant much favorable soil and climatic conditions $[1,12]$, the region has rich and diversified nature. All these factors facilitate to develop subtropical gardening (citrus-growing and fruit-growing) successfully in the region $[1]$.

Table 1. Different provisions of the hydrothermal coefficient in the vegetation period.

\begin{tabular}{|c|c|c|c|c|c|}
\hline \multirow{2}{*}{ Average Value } & \multicolumn{5}{|c|}{ Column2 } \\
\hline & 90 & 75 & 50 & 25 & 5 \\
\hline 1.5 & 1.0 & 1.3 & 1.5 & 1.9 & 3.0 \\
\hline 2.0 & 1.5 & 1.8 & 2.0 & 2.6 & 4.7 \\
\hline 2.5 & 1.9 & 2.3 & 2.5 & 2.9 & 5.0 \\
\hline 3.0 & 2.2 & 2.6 & 3.0 & 3.4 & 5.5 \\
\hline 3.5 & 2.5 & 3.0 & 3.5 & 4.0 & 5.9 \\
\hline
\end{tabular}

Soils of West Georgia mainly set out in the humid subtropical climate. Precipitation prevalence and the terrain was caused mainly in the coastal area, wetland soils spread, On the hills and the foothills of the subtropical organic red and yellow soils, mountainous part of the clobbered gray, where in which grow kiwi plantations, in addition to the swamp and organic soils, due to their heavy loamy soil properties.

The physical and geographical conditions allow us to determine whether the favorable natural conditions of a particular agricultural region, particularly in the deployment and management of high-quality Chinese ACTINIDIA harvest.

\section{Research Methods and Initial Data}

The agro-resources of some or other area can be estimated by using the multifactorial analysis. Therefore, it is important to use the method allowing most optimal selection of the right conditions [4]. In this respect, it is important to identify the leading factors and order them, by considering their functional priority. Consequently, in estimating the spreading area of kiwi culture, we think it relevant to fix the weighted distance from different points to the standard model by considering the priority of different factors (properties) and to group the objects depending on their proximity to the standard model.

The research was organized in several stages:

1. Creating the database of the agro-resource potential.

2. By using software MATLAB, calculating the "weighted" distances from each object to the standard model with the coefficients of priority, ranging the calculated values and grouping them by using Sterges formula.

3. Zoning the landscape units with the agro-resource potential favorable for kiwi to grow $[9,10,11]$ designing a large-scale landscape map), depending on the proximity to the standard model, based on GIS-analysis (Fig. 1).

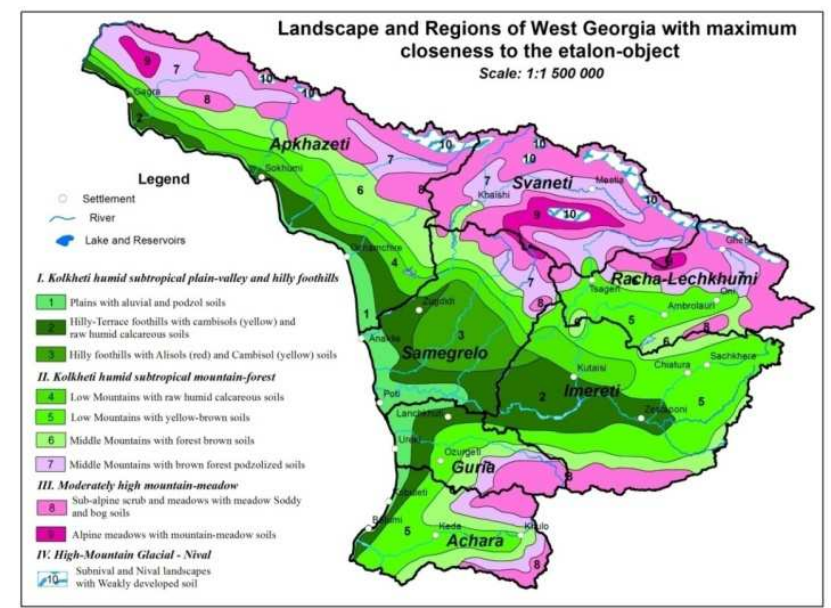

Figure 1. Landscape and Regions of West Georgia with maximum closeness to the etalon-object.

The research was based on six major parameters characterizing the agro-climatic potential of the area in the warm period of the year: absolute altitude of the location, sum of active temperature $\left(>10^{\circ} \mathrm{C}\right)$, amount of atmospheric precipitations, hydrothermal coefficient and soil $\mathrm{PH}$ value and prognosis yield per ha.

Data processing was carried out with the mathematical models in several stages:

- Formation of Matrix $\mathrm{A}=\left(a_{i j}\right)_{n \times m}$, where

$$
a_{i j}=K_{j}\left(O_{i}\right) ; i=\overline{1, n} ; j=\overline{1, m}
$$

$O_{1}, O_{2}, \ldots, O_{n}$ and $K_{1}, K_{2}, \ldots, K_{m}$ appropriately determine objects (territorial units) and selected quantitative characteristics in accordance with the aim of redistricting process.

- Data normalizing, because of range of numerical values variations corresponding to marks and features may differ from each other by several row.

$$
k_{j}\left(O_{i}\right)=\frac{K_{j}\left(O_{i}\right)}{K_{j}^{*}}, i=\overline{1, n}, j=\overline{1, m},
$$

where $K_{j}^{*}=\max \left\{K_{j}\left(O_{1}\right), K_{j}\left(O_{2}\right), \ldots, K_{j}\left(O_{n}\right)\right\}, j=1 \bar{m}$

- Composition of normalizing data matrix

$$
B=\left(b_{i j}\right)_{m \times n}, b_{i j}=k_{j}\left(O_{i}\right), i=\overline{1, n}, j=\overline{1, m}
$$

- Determination of priority coefficient for

i-characteristic $c_{j}, j=\overline{1, m}$, where

$$
\sum_{j=1}^{m} c_{j}=1
$$


- Formation of normalized values

$$
e_{i}=\frac{E_{j}}{K_{j}^{*}}, j=\overline{1, m},
$$

where $E_{j} \quad(j=\overline{1, m})$ are the components of etalon-object E.

- Calculation of ,weighed" distances from $U_{i}$ object to E etalon-object in Euclid $\mathrm{n}$ dimension space:

$$
d_{i}=\sqrt{\sum_{j=1}^{m} c_{j}\left(b_{i j}-e_{j}\right)^{2}, i}=\overline{1, n}
$$

- Determination of full range of distance dispersion from the object to etalon $d_{\max }-d_{\text {min }}$,

Where

$$
d_{\max }=\max \left\{d_{1}, d_{2}, \ldots, d_{n}\right\}, d_{\min }=\min \left\{d_{1}, d_{2}, \ldots, d_{n}\right\} .
$$

By Sturges formula $k=1+3,222 \log n$ for $\mathrm{n}$ optimal amount of grouping of objects were determined and determination of verge of grouping intervals:

$$
h=\frac{d_{\max }-d_{\min }}{k},
$$

- On the basis of complex characteristics the intervals for grouping of objects was defined:

$$
\left(r d_{\min }, r d_{\min }+h\right), r=\overline{1, k} .
$$

The study was based on agro-climatic potential warm period defining 6 basic parameters: elevation, the sum of active temperatures $(>100 \mathrm{C})$, atmospheric precipitation, hydrothermal coefficient, soil $\mathrm{PH}$ - indicator and forecast yield per hectare.

Kiwi (Chinese ACTINIDIA) of the highest, most optimal agro-climatic, natural conditions and expert analysis on the recommendation of specialists had developed a virtual standard-model the following indicators: the absolute height 400 meters, active temperatures $(>100)$ Subtotal - 35,000, precipitation (during the warm period) - 1,200 $\mathrm{mm}$, hydro-thermal coefficient (htc) - 3.0, soil PH- indicator - 6.0, forecast yield $1-30$ tons per hectare.

\begin{tabular}{|c|c|c|c|c|c|c|c|c|}
\hline Region & & Objects & $\begin{array}{l}\text { Place } \\
\text { Elevation, } \\
\text { m }\end{array}$ & $\begin{array}{l}\text { Sum of Active } \\
\text { Temperatures, } \\
\text { C0 }\end{array}$ & $\begin{array}{l}\text { Sum of } \\
\text { Atmospheric } \\
\text { Precipitation, } \\
\text { mm }\end{array}$ & $\begin{array}{l}\text { Hydrother } \\
\text { mal } \\
\text { Coefficient }\end{array}$ & $\begin{array}{l}\text { Soil } \\
\text { PH-indi } \\
\text { cator }\end{array}$ & $\begin{array}{l}\text { Prognosis } \\
\text { Yield, per } \\
\text { ton/ha }\end{array}$ \\
\hline \multirow{3}{*}{ Adjara } & I & $\begin{array}{l}\text { Batumi, Kobuleti, Chakvi, } \\
\text { Akhalsheni }\end{array}$ & $30-400$ & $4,000-4,500$ & 1,500 & $3-3.5$ & $7-8$ & $20-25$ \\
\hline & II & Chakvistavi, Keda & $400-700$ & $3,800-4,300$ & $1,400-1,500$ & $2.4-4$ & $5-6.5$ & $10-15$ \\
\hline & III & $\begin{array}{l}\text { Khulo, Purtio, } \\
\text { Gomarduli }\end{array}$ & $700-1,200$ & $3,100-3,300$ & $500-650$ & $1.5-2$ & $6-6.5$ & $5-7$ \\
\hline \multirow[b]{2}{*}{ Guria } & I & Ureki, Supsa & $5-100$ & $4,100-4,400$ & $1,200-1,400$ & $2.7-3.3$ & $5-7$ & $15-20$ \\
\hline & II & $\begin{array}{l}\text { Dablatsikhe, Anaseuli, } \\
\text { Atsana }\end{array}$ & $100-500$ & $4,100-4,200$ & $950-1,150$ & $2.3-2.7$ & $5-5.2$ & $10-15$ \\
\hline \multirow{2}{*}{ Imereti } & I & $\begin{array}{l}\text { Samtredia, Vani, Tskaltubo, } \\
\text { Khoni, Sakara, Dimi }\end{array}$ & $30-200$ & 4,500 & $600-1,000$ & $1.5-2$ & $5-7.5$ & $15-17$ \\
\hline & II & $\begin{array}{l}\text { Kharagauli, Sachkhere, } \\
\text { Tkibuli }\end{array}$ & $200-500$ & $3,500-4,000$ & $500-1,000$ & $2-3$ & $5-7$ & $10-12$ \\
\hline \multirow{3}{*}{ Samegrelo } & I & $\begin{array}{l}\text { Abasha, Anaklia, Senaki, } \\
\text { Kheta }\end{array}$ & $0-100$ & $4,300-4,600$ & $800-1,100$ & $1.8-2.4$ & $7-7.5$ & $15-20$ \\
\hline & II & $\begin{array}{l}\text { Chkhorotsku, Martvili, } \\
\text { Zugdidi }\end{array}$ & $100-700$ & $4,000-4,200$ & $1,000-1,200$ & $2.5-3$ & $5-7$ & $10-15$ \\
\hline & III & $\begin{array}{l}\text { Tsalenjikha, Mukhuri, } \\
\text { Lebarde }\end{array}$ & $700-1,500$ & $3,000-3,300$ & $600-700$ & $2-2.5$ & $6-7$ & $5-7$ \\
\hline \multirow{2}{*}{ Svaneti } & I & Khaishi, Lentekhi & $300-1,000$ & 3,300 & 760 & 2.3 & 7.0 & $4-5$ \\
\hline & II & Mestia, Becho, Koruldashi & $1000-1,700$ & $1,750-2,100$ & $1,700-2,100$ & $2.5-6.5$ & $7-7.5$ & $2-3$ \\
\hline \multirow{2}{*}{ Racha-Lechkhumi } & I & $\begin{array}{l}\text { Khvanchkara, Chrebalo, } \\
\text { Tsageri, Lentekhi }\end{array}$ & $500-900$ & $3,000-3,500$ & $650-750$ & $1.8-2.5$ & $6.5-7$ & $10-12$ \\
\hline & II & $\begin{array}{l}\text { Kharistvala, Oni, Ghebi, } \\
\text { Shovi, Kherga }\end{array}$ & $900-1,900$ & $1,100-2,200$ & $750-1,300$ & $3.5-7.5$ & 7.5 & $3-5$ \\
\hline \multirow[t]{2}{*}{ Aphkhazeti } & I & $\begin{array}{l}\text { Gagra, Gali, Gudauta, } \\
\text { Gulripshi, Ochamchire, } \\
\text { Sokhumi }\end{array}$ & $30-300$ & $4,000-4,500$ & $850-1,000$ & $1.5-2.5$ & $5-7.5$ & $20-25$ \\
\hline & II & Lata, Kvezani & $300-500$ & $3,600-4,000$ & $750-1,450$ & $2.9-3.6$ & $5-7$ & $10-15$ \\
\hline
\end{tabular}

Agro-climatic characteristics $[6,13]$ was processed in West Georgia for 7 regions - Adjara, Guria, Imereti, Samegrelo, Svaneti, Racha and Abkhazia (Table 2).

Table 2. Hypsometric distribution of agroclimatic properties in the warm period of the year.

As the table shows, closest to the standard model is the second hypsometric zone of Ajara, Apkhazeti, Guria, Imereti and Samegrelo (from 100 to 400-500 m); however, the I zone in Guria region (if ignoring a little too much abundant moisture in it) is quite close to the II zone with humid subtropical landscapes (see map zones: 2,3 ) of a hilly-Terrace 
piedmont with Alisols, Cambisols and Raw humus Calcareous (the later type of soil is particularly widely spread in some parts of Samegrelo, Imereti and also in part of Apkhazeti). As for Racha-Lechkhumi and Svaneti, their natural conditions are less favorable for kiwi to grow and develop, with the I zone $(700-1000 \mathrm{~m})$ with the Kolkheti humid subtropical mountain-forest landscapes with humid yellow-brown and Raw humus Calcareous soils being closest to the standard model (see map zones 4, 5), As for the rest hipsometriul zones (map \# 6, 7, 8, 9, 10) are useless kiwi culture zones $(7,8)$, therefore are away from Etalon-model (Fig. 2).

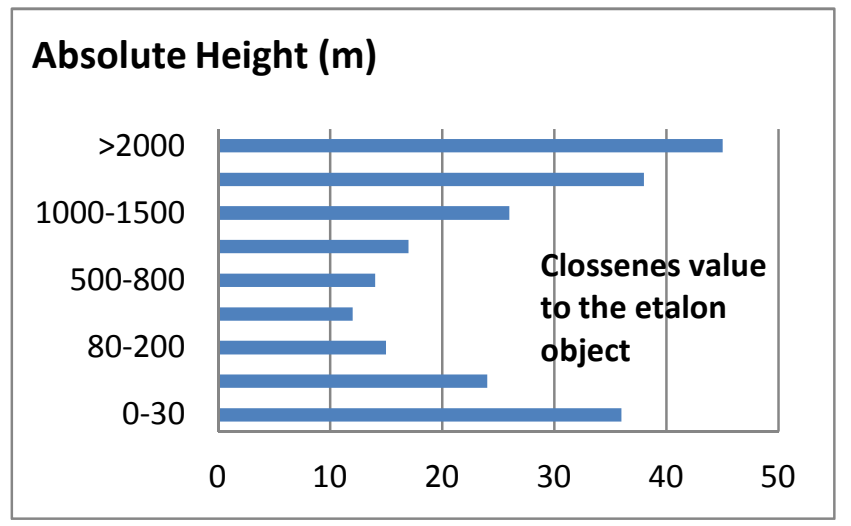

Figure 2. Closeness value to the etalon-object according to different altitudes in terms of agri resource potential4. Conclusion

Several important results were gained as a result of the study:

- The methods to estimate the agro-resource potential of the territorial units were developed. The methods are based on the calculation of the weighted distances with a coefficient of priority of factors to the standard object;

- By using the said method, the regularities in the territorial distribution of Actinidia Chinensis Planch culture in West Georgia, hypsometric stages with high potential, landscape types and regions were identified. Detected different potential of Hypsometric area, landscape types and regions;

- Based on the database of the agro-resource potential and GIS-technologies, a large-scale landscape map of the territory of West Georgia was designed.

\section{Acknowledgements}

This research would not have been possible without the support of many people and also without using many scientific researches done by the staff of the Geographical Department (Faculty of Exact and Natural Sciences) of Ivane Javakhishvili Tbilisi State University and Institute of Phytopathology and Biodiversity of Batumi Shota Rustaveli State University. The authors of the work express their gratitude to all them.

\section{References}

[1] G. Gagua. "Kolkheti agro-climatic conservation problems", Tbilisi, Metsniereba, 1988, pp. 7-13. In Georgian.

[2] V. Papunidze. "Kiwi", Tbilisi, Metsniereba, 1998, 97 p. In Georgian.

[3] F.F. Davitaia. "Prediction provide heat and some of the problems of the seasonal nature", Gidrometeoizdat, 1964, 132 p. In Russian.

[4] I.R. Arkhipov, N.I. Bladjko, etc. "Mathematical Methods in Geography". Kazan University, 1976, 352 p. In Russian.

[5] G.A. Arveladze. "Mathematical modeling of hydrometeorological processes of formation of a crop of perennial crops and optimization of the technology of their cultivation". Tbilisi, 2006, pp. 64- 69. In Georgian.

[6] G. Meladze, M. Meladze. "Agroklimatic resources of western regions of Georgia". Tbilisi, Institute of Hidrometeorology at the Technical University. 2012, pp. 248-426. In Georgian.

[7] Z. Seperteladze, E. Davitaia, M. Alpenidze. "Nature Management Zoning of Upper Svaneti", Geographical Environment. Annals of Agrapian Science, Vol. 11, Nom. 2, 2013, pp. 12-15.

[8] Z. Seperteladze, E. Davitaya., T. Alecsidze, N. Ruxadze. "Problems Landsscape Ecological and Natural Zoning". Annals of Agrapian Science. Vol.8, No. 6. 2012, pp. 88-94.

[9] T. Urushadze, Z. Seperteladze, E. Davitaya. Natural Resource Potential of Western Georgia and Territorial Managment of Agro Landscapes. Bulletin Georgian National Academy of Sciences vol.4. No. 1. Tbilisi, 2012, pp. 74-78.

[10] D. Nikolaishvili, Z. Seperteladze, E. Davitaia, T. Kikvadze, Ts. Donadze.. "Evaluation of Agri Resource Potential of Georgia's Landscapes by the Use of Mathematical methods". IJSR: International Journal of Scientific Researches, vol. 2, Issue: 12, 2013, pp. 251-255. www.theglobaljournals.com.

[11] Z. Seperteladze, E. Davitaia, T. Aleksidze, N. Rukhadze, G. Gaprindashvili. "Assessment of agro-resource potential of the western Georgia and physical-geographical zoning". IJSR: International Journal of Scientific Researches, vol. 3., issue: 6, June, 2014, pp. 170-171.

[12] D. Nikolaishvili, L. Matchavariani. "Humus Reserves and Their Distribution in the Landscapes of Georgia". Eurasian Soil Science, Vol. 43, No. 1, January. 2010, pp. 39-48.

[13] E. Elizbarashvili, Z. Chavchanidze., M. Elizbarashvili, R. Maglakelidze, N. Sulkhanishvili, Sh. Elisbarashvili. "Soil Climatic Zoning of Georgia". Eurazian Soil Science, vol. 39, № $10,2006$. 